\title{
Constitutively Active Mu Opioid Receptors Mediate the Enhanced Conditioned Aversive Effect of Naloxone in Morphine-Dependent Mice
}

\author{
James R Shoblock*,' and Nigel T Maidment' \\ 'Department of Psychiatry and Biobehavioral Science, University of California Los Angeles, Los Angeles, CA, USA
}

\begin{abstract}
Naloxone administration produces a robust conditioned place aversion (CPA) in opiate-naive rodents by blocking the action of enkephalins at mu opioid receptors. This aversive response is potentiated by prior exposure to morphine. In vitro studies indicate that morphine treatment may promote constitutive activity of mu opioid receptors. We hypothesized that such enhanced constitutive activity in vivo may underlie the increased aversive property of naloxone by uncovering the inverse agonist property of this drug. The CPA produced by naloxone was compared with that produced by the neutral antagonists 6-alpha- and 6-beta-naloxol in mice with and without prior morphine exposure. While all three drugs produced CPA, only naloxone CPA was enhanced by morphine given $20 \mathrm{~h}$ prior to each naloxone injection. Furthermore, only naloxone produced withdrawal jumping when given $20 \mathrm{~h}$ after morphine, even though 6 alpha-naloxol was able to produce jumping when given $4 \mathrm{~h}$ after morphine. These data suggest that morphine may enhance naloxone CPA by increasing levels of constitutively active mu receptors and further support the role of such constitutive activity in mediating naloxone-precipitated physical withdrawal. Such long-term changes in constitutive activity of the mu receptor induced by exogenous opiate exposure may thus be an important factor in hedonic homeostatic dysregulation proposed to underlie the addictive process. Neuropsychopharmacology (2006) 3 I, I7I-177. doi:I 0. I038/sj.npp. I 300782; published online I June 2005
\end{abstract}

Keywords: naloxone; morphine; opiate dependence; opiate addiction; constitutive active receptor; conditioning

\section{INTRODUCTION}

It has been hypothesized, based largely on work carried out on cellular model systems, that the mu opioid receptor, along with other G-protein-coupled receptors, may exist in a constitutively active state where a basal level of signaling occurs in the absence of agonist binding (see Seifert and Wenzel-Seifert (2002) for a review). Exposure to agonists, such as morphine, has been shown to produce an increase in the number of constitutively active mu receptors that outlasts agonist treatment and that is most likely due to a change in receptor phosphorylation (Cruz et al, 1996; Wang et al, 2001, 1994, 1996, 1999).

However, the physiological significance of constitutively active mu receptors in vivo remains unclear. It has been proposed that the increase in constitutively active mu receptors induced by morphine treatment is important in

\footnotetext{
*Correspondence: Dr JR Shoblock, Department of Psychiatry and Biobehavioral Sciences, UCLA Neuropsychiatric Institute, 760 Westwood Plaza, Los Angeles, CA 90024, USA, Tel: + I 310206 7890, Fax: + I 310825 7067, E-mail: shoblock@ucla.edu

Received 13 January 2005; revised I 5 April 2005; accepted 18 April 2005

Online publication: 22 April 2005 at http://www.acnp.org/citations/ NPP042 I 05050026/default.pdf
}

the development of physical dependence to morphine (Cruz et al, 1996; Wang et al, 1994). In support of this, inverse mu agonists were shown to produce greater withdrawal jumping compared to neutral antagonists (Wang et al, 2001, 2004), and a neutral antagonist attenuated the withdrawal jumping produced by the inverse agonist naloxone (Bilsky et al, 1996; Wang et al, 1994). Such physical withdrawal symptoms are one component of what is now recognized as a more complex opiate dependence syndrome including disruption of affective state (Schulteis and Koob, 1996). Interesting in this regard is the observation that morphine pretreatment potentiates the aversive property of naloxone, as demonstrated by the place conditioning paradigm (Azar et al, 2003; Blokhina et al, 2000; Parker et al, 2002; Parker and Joshi, 1998; Schulteis et al, 1994). Importantly, the increase in the aversive effect of naloxone has been shown to persist for $48 \mathrm{~h}$ after morphine administration (Parker et al, 2002), by which time very little morphine should remain in the system (Iwamoto and Klaassen, 1977). Such enhanced aversion is thought to reflect the negative motivational and affective state associated with morphine withdrawal (Gracy et al, 2001; Mucha and Walker, 1987) and may be a product of the counteradaptive processes that lead to dysregulation of hedonic homeostasis (Kreek and Koob, 1998). As important 
as this may be to compulsive drug seeking and addiction (Kreek and Koob, 1998), the mechanisms underlying the increase in naloxone CPA after morphine pretreatment are unknown.

Naloxone has been shown to act as an inverse agonist at the mu receptor in vitro, stimulating cAMP levels and inhibiting GTP $\gamma \mathrm{S}$ binding in morphine-pretreated, but not untreated, tissue (Liu and Prather, 2001; Raehal et al, 2005; Wang et al, 2001, 2004, 1994). Such uncovering of the inverse agonist properties of naloxone by morphine pretreatment is predicted, since morphine would be expected to increase the number of constitutively active mu receptors (for a review, see Kenakin, 2004). Therefore, the possibility that constitutively active mu receptors, formed after morphine treatment, mediate the heightened naloxone-precipitated 'motivational' withdrawal was examined in the current study.

The aversive property of the inverse agonist, naloxone, was compared with that of two neutral antagonists, 6-alphaand 6-beta-naloxol, with and without prior repeated morphine exposure. 6-Alpha- and 6-beta-naloxol were previously shown to be neutral antagonists at the mu receptor in vitro, with no affect on cAMP levels or GTP $\gamma S$ binding, regardless of morphine pretreatment (Wang et al, 2001). and were chosen as the neutral antagonists for this study because they are also structural analogues of naloxone, with similar affinity for the mu receptor, and are systemically active (Wang et al, 2001). In a parallel series of experiments, we sought to confirm and expand previous reports on the role of constitutively active mu receptors in mediating precipitated physical withdrawal symptoms.

\section{MATERIALS AND METHODS}

\section{Subjects}

Adult male C57BL/6 mice (8-10 weeks old at start of experiment), obtained from Jackson Laboratories (Bar Harbor, ME), were used. All experiments were carried out during the light phase of a 12/12 h light/dark cycle (07001900). Food and water were available ad libitum. All procedures complied with the NIH Guide for Care and Use of Laboratory Animals and the UCLA IACUC.

\section{Drugs}

Naloxone (0.05-100 mg/kg; Sigma), 6-beta-naloxol (0.05$10 \mathrm{mg} / \mathrm{kg}$; NIDA), 6-alpha-naloxol (0.05-100 mg/kg; NIDA), and morphine $(20-100 \mathrm{mg} / \mathrm{kg})$ were dissolved in saline and administered subcutaneously (s.c.) at $10 \mathrm{ml} / \mathrm{kg}$. All doses refer to the weight of the salt.

\section{CPA Protocol}

Details of the conditioning apparatus, providing automated recording of subject location (Coulbourn Instruments, Allentown, PA), were described previously (Skoubis et al, 2001). Briefly, a square arena was divided into three chambers: a neutral start chamber (gray walls and floor), and two conditioning chambers (black and white checkers and black and white cow patterns) that were accessible via the neutral chamber through guillotine doors. The two conditioning chambers were also distinguishable on the basis of odor - almond or lemon scent (McCormick and Co., Hunt Valley, MD).

Animals were habituated to the apparatus on the first day by being placed in the gray chamber and given free access to all three chambers for $15 \mathrm{~min}$. Over the next 6 days, animals were conditioned 3 times to either drug (naloxone 0.05$10 \mathrm{mg} / \mathrm{kg}$, 6-beta-naloxol $0.05-10 \mathrm{mg} / \mathrm{kg}$, or 6-alpha-naloxol $0.05-1 \mathrm{mg} / \mathrm{kg}$, or saline as a control) in one conditioning chamber and saline in the opposite chamber, on alternating days starting with saline. The drug chamber was chosen randomly. Immediately after each injection, the animals were confined to the chamber for $30 \mathrm{~min}$ and observed for presence or absence of jumping behavior. On the 8th day, animals were tested for CPA in a drug-free state. Animals were placed in the gray chamber with free access to all three chambers for $15 \mathrm{~min}$ and the time spent in each chamber was recorded.

Animals received morphine $(20 \mathrm{mg} / \mathrm{kg})$ or saline $20 \mathrm{~h}$ before each drug and saline conditioning session and $20 \mathrm{~h}$ before the CPA test session, in the home cage. Morphine was given $20 \mathrm{~h}$ before the CPA test session to maintain consistency with the conditioning sessions thereby avoiding any alterations to the motivational-state of the animal that could interfere with the expression of CPA.

\section{Withdrawal Jumping Protocol}

Withdrawal jumping induced by 6-alpha-naloxol and naloxone was quantified in a separate series of experiments under two different conditions. In the first case (A), these drugs were administered $4 \mathrm{~h}$ after the second of two morphine $(100 \mathrm{mg} / \mathrm{kg})$ injections. This was carried out to compare the dose-response relationships for the two drugs in inducing withdrawal jumping under conditions where morphine remained in the system. In the second case (B), the drugs were administered $20 \mathrm{~h}$ after the last of seven morphine $(20 \mathrm{mg} / \mathrm{kg})$ injections to examine differences in the propensity of these two drugs to induce jumping at a time when morphine levels would be greatly reduced. These experiments were conducted in two separate groups of animals.

In the first experiment (A) animals received an injection of morphine $(100 \mathrm{mg} / \mathrm{kg}$, s.c.) on day 1 and $3 \mathrm{~h}$ later were habituated to clear-cylindrical chambers for $1 \mathrm{~h}$. On day 2, $24 \mathrm{~h}$ after the first morphine injection, animals received a second injection of morphine $(100 \mathrm{mg} / \mathrm{kg}$, s.c.), and $3 \mathrm{~h}$ later were habituated to the chambers again. During this time, the number of spontaneous jumps was recorded. After $1 \mathrm{~h}$, animals received an injection of naloxone $(10-100 \mathrm{mg} / \mathrm{kg}$, s.c.) or 6-alpha-naloxol (10-100 $\mathrm{mg} / \mathrm{kg}$, s.c.) and the number of jumps over $30 \mathrm{~min}$ were recorded.

In the second experiment (B) animals were injected with morphine $(20 \mathrm{mg} / \mathrm{kg}$, s.c.) on days $1-7$. On day $7,19 \mathrm{~h}$ after the sixth morphine injection, animals were placed in the chamber for a $1 \mathrm{~h}$ habituation period. On day $8,19 \mathrm{~h}$ after the seventh morphine injection, animals were placed in the chamber for $1 \mathrm{~h}$. During this time, the number of spontaneous jumps was recorded. At the end of the $1 \mathrm{~h}$, animals were injected with naloxone $(10-100 \mathrm{mg} / \mathrm{kg}$, s.c.) or 
6-alpha-naloxol (10-100 mg/kg, s.c.) and jumps were recorded for $30 \mathrm{~min}$.

\section{Data Analysis}

CPA was measured as the time spent in the drug chamber on CPA test day (day 8), without reference to preconditioning/habituation data, and the effect of morphine pretreatment was analyzed using a two-way analysis of variance (ANOVA) for morphine/saline pretreatment $\times$ dose, followed by the Student-Newman-Keuls (SNK) post hoc test when appropriate. The presence of jumping during the drug conditioning session was recorded in a binary manner: one or more complete jumps in which all four paws left the ground was recorded as 'behavior present' while the absence of any such jumps was recorded as 'behavior not present'. The percent of animals expressing this behavior was then analyzed using a Fisher exact test with the Bonferroni correction for multiple comparisons. For experiments focused specifically on jumping, the total number of jumps were recorded. For experiment $A$, the total number of jumps was analyzed using a three-way ANOVA for drug $\times$ dose $\times$ before/after treatment, with repeated measures on before and after treatment, followed by an SNK post hoc test when appropriate. For experiment $B$, number of jumps was analyzed using Wilcoxon's matched pairs test comparing the number of jumps before and after drug treatment and Mann-Whitney $U$-test comparing treatment. These nonparametric tests were used due to the lack of variance in the 6-alpha-naloxol group resulting in unequal variances in the two groups. Analyses were carried out using Statistica software (Tulsa, OK).

\section{RESULTS}

\section{Habituation}

Animals demonstrated a small but significant bias (325 vs $302 \mathrm{~s}$ ) for the checker-patterned chamber over the cowpatterned chamber during the preconditioning exposure. However, there were no significant differences between the treatment groups in the designation of the drug-paired chamber as cow or checker. Moreover, there was no significant difference between time spent in the future vehicle-paired chamber and time spent in the future drugpaired chamber during the preconditioning exposure. Most importantly, there was no significant difference in time spent in the future drug-paired chamber during preconditioning between the treatment groups.

\section{Chronic Morphine Potentiated Naloxone CPA}

Naloxone dose dependently produced CPA compared to the control group conditioned with saline, regardless of pretreatment (Figure 1; main effect of dose, $\mathrm{F}_{4,75}=7.33$, $p<0.00005)$. This effect of naloxone was significant at all but the lowest dose tested $(p<0.05, p<0.007$, and $p<0.0002$ for $0.1,1$, and $10 \mathrm{mg} / \mathrm{kg}$, respectively, SNK post hoc). There was a main effect of pretreatment, such that morphinepretreated animals displayed greater CPA to naloxone compared to saline-pretreated animals conditioned with naloxone $\left(F_{1,75}=9.79, p<0.003\right)$. Morphine pretreatment

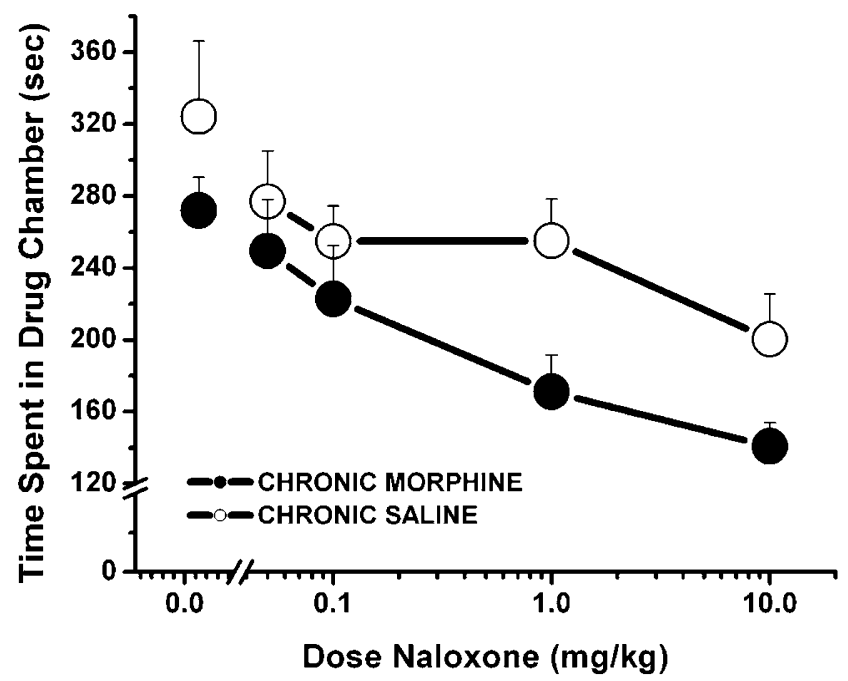

Figure I Morphine pretreatment enhanced CPA to naloxone. Naloxone dose-dependently decreased the time spent in the drug-paired chamber relative to animals injected with saline in both chambers $(0 \mathrm{mg} / \mathrm{kg})$ ( $p<0.02$ vs corresponding saline group, SNK post hoc). The amplitude of this aversion was increased in animals receiving morphine $20 \mathrm{~h}$ prior to each naloxone conditioning session ( $p<0.003$, main effect of pretreatment). $N=8-\mid$ | per group.

did not affect control animals conditioned to saline in each chamber $\left(\mathrm{F}_{1,18}=1.65, p=0.21\right)$.

\section{Chronic Morphine had no Effect on 6-Alpha- or 6-Beta-Naloxol CPA}

6-Beta-naloxol also produced CPA (Figure 2a; main effect of dose, $\left.\mathrm{F}_{4,69}=3.93, p<0.006\right)$ but was effective only at the highest dose tested $(p<0.005$ for $10 \mathrm{mg} / \mathrm{kg}$ vs saline conditioned animals, SNK post hoc). Morphine pretreatment had no effect on the CPA produced by 6-beta-naloxol $\left(\mathrm{F}_{1,69}=0.49, p=0.48\right)$. 6-Alpha-naloxol also produced CPA compared to saline conditioned animals at the highest dose tested (Figure 2b; main effect of dose, $\mathrm{F}_{3,48}=8.68$, $p<0.0002 ; p<0.003$ for $1 \mathrm{mg} / \mathrm{kg}$ vs saline conditioned animals, SNK post hoc) in a manner that was not affected by morphine pretreatment $\left(\mathrm{F}_{1,48}=0.02, p=0.89\right)$.

\section{Naloxone Produced Jumping in more Animals than 6-Alpha- and 6-Beta-Naloxol During Conditioning}

During the third CPA drug conditioning session on day 7 , naloxone dose-dependently produced withdrawal jumping in the morphine-pretreated mice with $100 \%$ of the animals jumping at the highest dose tested (Figure 3, $p<0.0001$, Fisher's exact test, $\alpha=0.0125$ with Bonferroni correction, $10 \mathrm{mg} / \mathrm{kg}$ naloxone $v s$ saline). 6-Beta-naloxol did not produce jumping at any dose tested. 6-Alpha-naloxol, at $1 \mathrm{mg} / \mathrm{kg}$, produced jumping in one out of the six morphinepretreated animals, an effect which was not significant ( $p=0.35$, Fisher exact test, $\alpha=0.017$ with Bonferroni correction, $1 \mathrm{mg} / \mathrm{kg}$ 6-alpha-naloxol $v s$ saline). None of the saline-pretreated animals showed jumping behavior during conditioning to any of the three drugs. Similarly, morphinepretreated animals conditioned with saline failed to display spontaneous jumping. 

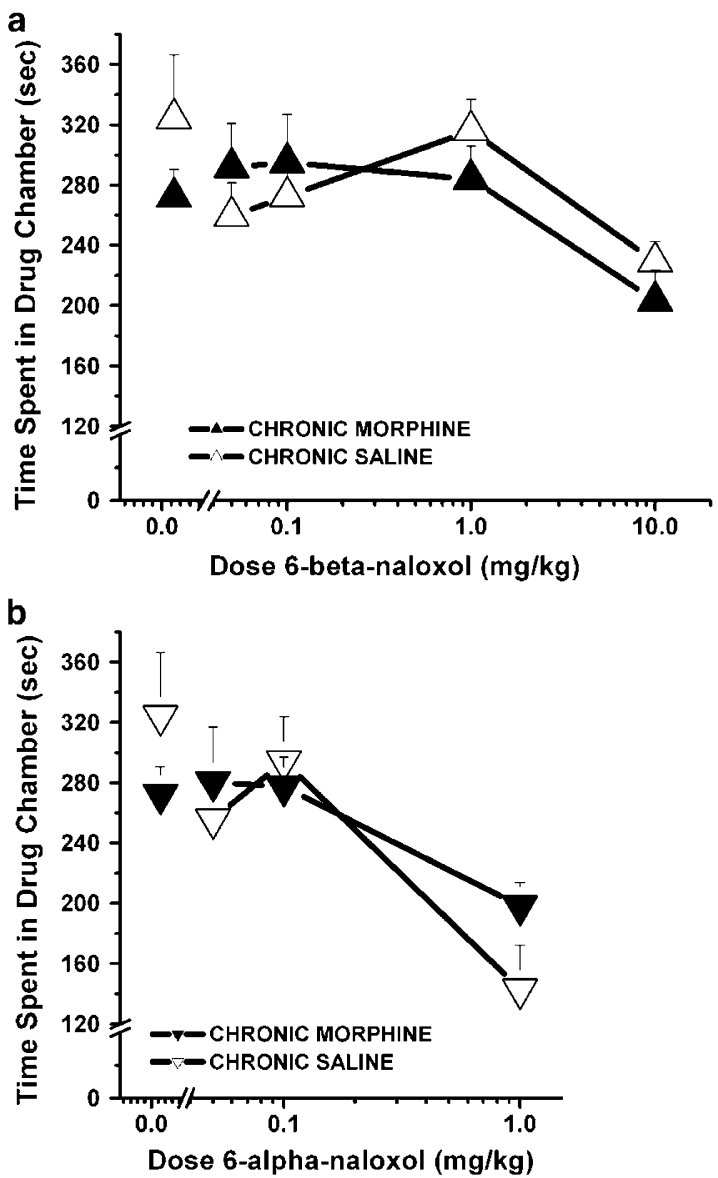

Figure 2 Morphine pretreatment had no effect on CPA to neutral antagonists. 6-Beta-naloxol (a) and 6-alpha-naloxol (b) decreased the time spent in the drug-paired chamber at doses of 10 and $1 \mathrm{mg} / \mathrm{kg}$, respectively, relative to animals treated with saline in both chambers $(0 \mathrm{mg} / \mathrm{kg}$, shown also in Figure I), $(p<0.005$ and $p<0.0003$ for 6-beta-naloxol and 6-alphanaloxol vs saline, respectively, SNK post hoc). Morphine-pretreated animals did not differ from saline-pretreated animals in either case $(p=0.48$ and 0.89 , main effects of pretreatment). $N=6-1$ I per group.

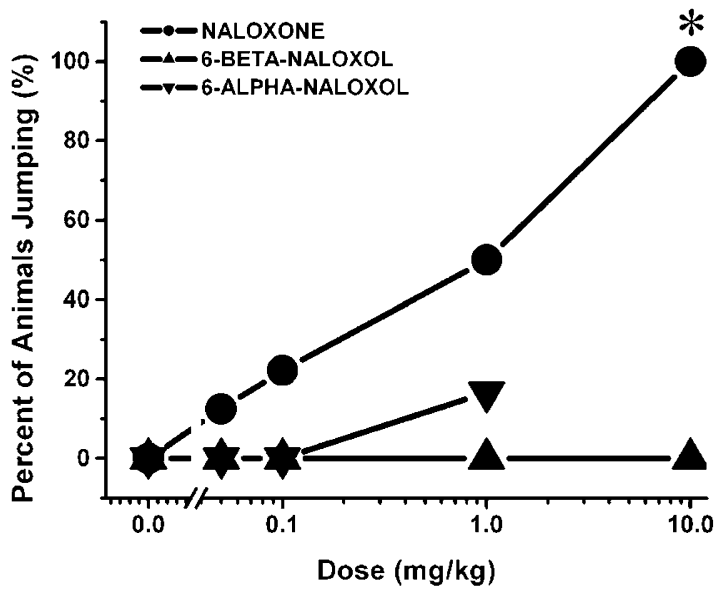

Figure 3 Withdrawal jumping during the third drug conditioning session in morphine-pretreated mice. Naloxone dose-dependently produced jumping $20 \mathrm{~h}$ after morphine pretreatment during the third drug conditioning session ( $*<0.000$ I, vs saline, Fisher's exact test, $\alpha=0.0125$ with the Bonferroni correction). 6-Alpha- and 6-beta-naloxol did not produce significant jumping.

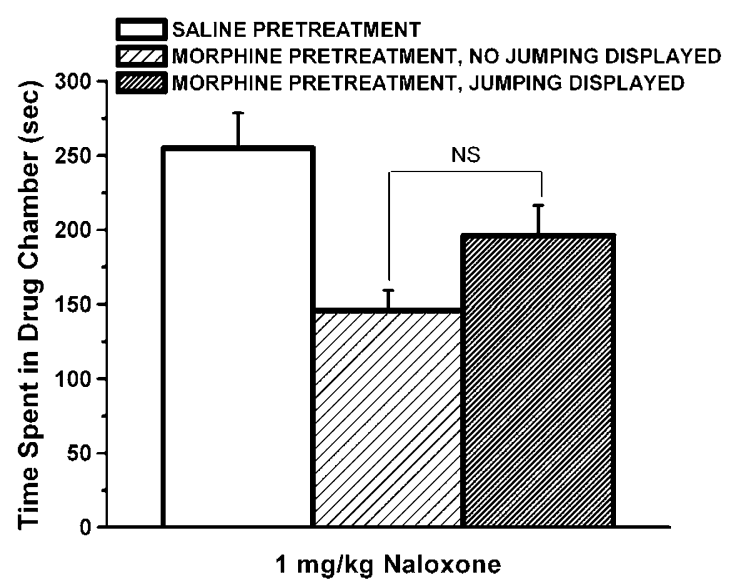

Figure 4 The enhancement of naloxone CPA by morphine pretreatment was not due to the presence of physical withdrawal during drug conditioning. There was no significant difference in the amplitude of the CPA produced by $1 \mathrm{mg} / \mathrm{kg}$ naloxone between animals that displayed withdrawal jumping compared to those that showed no such behavior.

The degree of CPA produced by naloxone did not correlate positively with the presence of physical withdrawal; there was no significant difference in the amplitude of CPA produced by $1 \mathrm{mg} / \mathrm{kg}$ naloxone between animals that showed withdrawal jumping and those animals that did not (Figure 4; $\mathrm{F}_{1,6}=1.70, p=0.24$ ).

Naloxone Produced more Jumping than 6-Alpha-Naloxol when Administered $20 \mathrm{~h}$, but not $4 \mathrm{~h}$, after Morphine

Both naloxone and 6-alpha-naloxol precipitated withdrawal jumping $4 \mathrm{~h}$ after the second of two daily injections of morphine $(100 \mathrm{mg} / \mathrm{kg}$, s.c.) with similar efficacy and potency (Figure 5a; main effect of before and after treatment, $\mathrm{F}_{1,28}=36.66, p<0.000002$, but no main effect of drug or drug $\times$ dose interaction, $p>0.82)$. When administered $20 \mathrm{~h}$ after the last of seven daily morphine $(20 \mathrm{mg} / \mathrm{kg}$, s.c.) injections, naloxone produced significant jumping (Figure 5b; $z=2.62, p<0.009$, Wilcoxon's matched pairs test comparing before and after treatment); the doseresponse curve was similar in shape to that obtained when tested $4 \mathrm{~h}$ after $100 \mathrm{mg} / \mathrm{kg}$ morphine, but with jumping in fewer animals. 6-Alpha-naloxol did not produce jumping at any dose tested and differed significantly from naloxone $(z=2.41, p<0.02$, Mann-Whitney $U$-test $)$.

\section{DISCUSSION}

The conditioned aversive property of naloxone administration in drug-naïve animals is well-described (Grevert and Goldstein, 1977; Mucha et al, 1982, 1985; Mucha and Iversen, 1984; Mucha and Herz, 1985; Mucha and Walker, 1987; Iwamoto, 1985; Parker and Rennie, 1992) and suggests the presence of tonic activity within endogenous opioid systems contributing to a basal hedonic or affective state. We previously provided evidence in knockout models that naloxone produces its aversive effects by blocking the action of enkephalins at the mu opioid receptor (Skoubis 

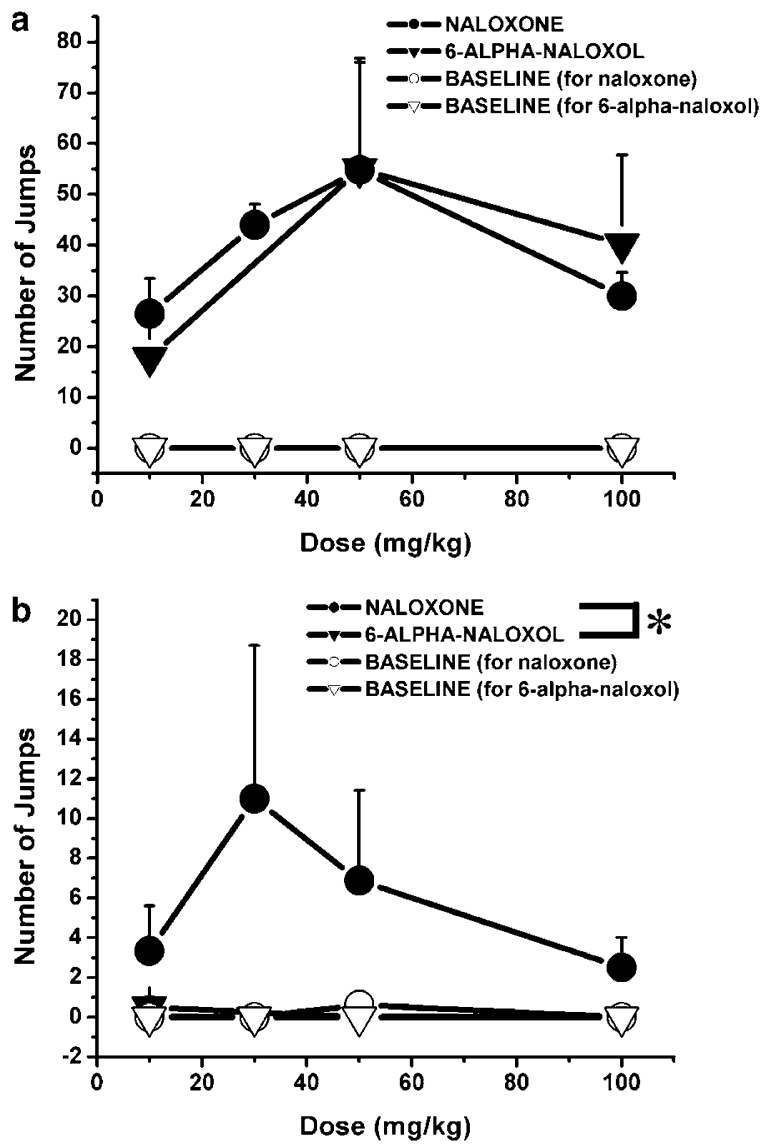

Figure 5 Withdrawal jumping produced by naloxone and 6-alphanaloxol. (a) In a separate experiment, both naloxone and 6-alpha-naloxol produced withdrawal jumping when administered $4 \mathrm{~h}$ after the second of two daily injections of morphine $(100 \mathrm{mg} / \mathrm{kg})$, with similar efficacy and potency. (b) When tested $20 \mathrm{~h}$ after the last of seven daily morphine $(20 \mathrm{mg} / \mathrm{kg})$ injections in a separate group of mice, naloxone similarly produced withdrawal jumping whereas 6-alpha-naloxol did not produce any jumping. $\mathrm{N}=5-9$.

et al, 2001, 2005). In the current study, we provide evidence that in the morphine-dependent state, naloxone's aversive effect may be due in part to its inverse agonist action at constitutively active mu receptors.

The mu opioid receptor has been shown in vitro to couple to signaling mechanisms in the absence of ligand, and this level of mu receptor constitutive activity was enhanced following exposure to agonists such as morphine (Liu and Prather, 2001; Raehal et al, 2005; Wang et al, 2001, 2004, 1994). It has been hypothesized that this increase in constitutively active receptors following morphine administration plays a role in morphine dependence (Cruz et al, 1996; Wang et al, 1994). However, it is increasingly apparent that psychological as well as physical syndromes associated with opiate abstinence play a significant role in relapse to chronic drug intake (Markou et al, 1993; Schulteis and Koob, 1996). The conditioned aversive effect of antagonist-precipitated opiate withdrawal in animal models is considered reflective of this negative affective state (Azar et al, 2003).

As described above, naloxone conditions aversive responses in opiate-naive animals but previous studies have shown that morphine pretreatment increases the CPA produced by naloxone (Azar et al, 2003; Blokhina et al, 2000; Parker et al, 2002; Parker and Joshi, 1998; Schulteis et al, 1994). Importantly, such potentiation of naloxone's aversive effect persists when naloxone is administered up to at least $48 \mathrm{~h}$ after morphine treatment (Parker et al, 2002), a time when morphine is effectively removed from the system (Iwamoto and Klaassen, 1977). We hypothesized that this enhancement of naloxone's aversive action could be due to a morphine-induced increase in constitutively active mu opioid receptors rendering naloxone's inverse agonist property effective.

This was tested in the current study by comparing the activity of naloxone against two structural analogues of naloxone, 6-alpha- and 6-beta-naloxol, in the CPA paradigm, with and without prior morphine treatment. 6-Alphaand 6-beta-naloxol are hydroxylated derivatives of naloxone and have affinities and selectivities for the mu receptor similar to naloxone itself (Wang et al, 2001). However, whereas naloxone exhibits inverse agonist properties in cyclic AMP and GTP $\gamma$ S assays in vitro after morphine exposure (Wang et al, 2001), 6-alpha- and 6-beta-naloxol remain neutral antagonists regardless of morphine treatment (Wang et al, 2001). In our study, naloxone dosedependently produced CPA and, consistent with previous results (Azar et al, 2003; Blokhina et al, 2000; Parker et al, 2002; Parker and Joshi, 1998; Schulteis et al, 1994), morphine pretreatment significantly enhanced the CPA produced by naloxone. Importantly, this enhancement was observed when naloxone was administered $20 \mathrm{~h}$ after morphine pretreatment, at a time when little or no morphine should remain in the brain (Handal et al, 2002). While both 6-alpha- and 6-beta-naloxol were shown to be effective at producing CPA, morphine pretreatment had no affect on the CPA produced by these drugs.

Observation of the animals during the conditioning sessions indicated that while naloxone dose-dependently produced withdrawal jumping following morphine treatment, 6-alpha- and 6-beta-naloxol produced no such behavior, even at doses that were just as effective as naloxone at producing CPA. While this corroborated a previous report investigating these drugs in physical withdrawal paradigms (Wang et al, 2001), we were concerned that doses of 6-alpha- and 6-beta-naloxol effective at producing withdrawal jumping may lay outside their potency range in producing CPA. We therefore conducted additional experiments employing higher doses. We also considered it important to compare doses of the drugs that were comparable in terms of their effectiveness as antagonists in the jumping assay. Therefore, we first tested the effectiveness of naloxone and 6-alpha-naloxol to induce jumping when administered $4 \mathrm{~h}$ after injection of a large dose of morphine $(100 \mathrm{mg} / \mathrm{kg})$, that is, when some morphine would still be present in the system. Under these conditions, both drugs produced withdrawal jumping, with similar potency and efficacy. When tested $20 \mathrm{~h}$ after the last daily injection of a lower dose of morphine $(20 \mathrm{mg} / \mathrm{kg})$, a time when little or no morphine should remain (Handal et al, 2002), naloxone retained its ability to produce significant levels of withdrawal jumping. However, when 6-alpha-naloxol was tested in this manner no withdrawal jumping was observed, even though the same doses effective at producing jumping in the earlier experiment were 
employed. These data are consistent with the proposed role of constitutively active mu opioid receptors in mediating naloxone-precipitated physical withdrawal (Cruz et al, 1996; Wang et al, 2001; Wang et al, 1994), and further substantiate these previous reports by showing that the difference between the neutral antagonists and inverse agonists are not simply due to an inherent inability of the neutral antagonists to produce jumping. Here, the neutral antagonist was shown to be capable of producing jumping when there was exogenous agonist available to block.

These data therefore support the idea that repeated morphine administration enhances the CPA produced by naloxone by inducing constitutively active $\mathrm{mu}$ receptors. Indeed, the presence of such constitutively active receptors $20 \mathrm{~h}$ after morphine could be considered a homeostatic mechanism ameliorating the aversive effects of spontaneous opiate withdrawal. The induction of constitutively active mu receptors may therefore play a key role in the chronic opiate-induced hedonic homeostatic dysregulation or allostasis proposed to underlie the addicted state (Koob and Le Moal, 2001).

Other possible explanations for the results must be considered, however. It is possible that pharmacological actions of 6-alpha- and 6-beta-naloxol differ from naloxone in other respects. For example, there is some evidence that 6-alpha-naloxol is a weak agonist (Chatterjie and Inturrisi, 1975). Such activity might result in less CPA following morphine pretreatment by substituting for morphine and alleviating morphine withdrawal. However, 6-beta-naloxol was reported to have no such partial agonist activity (Chatterjie and Inturrisi, 1975) and naloxone itself has been reported to be a weak agonist (Fukuda et al, 1998; Liu and Prather, 2001; Wang et al, 2004) making such an explanation unlikely. Since the receptor binding profiles of 6-alphaand 6-beta-naloxol are incomplete, it is possible that these drugs interact, differentially from naloxone, with other, non-mu opioid, receptor systems resulting in counteraction of the morphine enhancement of both CPA and withdrawal jumping. However, since the only known pharmacological difference between naloxone and its 6-hydroxyl derivatives is the difference in negative intrinsic activity, the hypothesis that naloxone acts as an inverse agonist to produce greater aversion and physical withdrawal is the best supported theory.

In summary, we have provided data consitent with the hypothesis that constitutively active mu opioid receptors, induced by repeated morphine administration, may contribute to the enhanced aversive property of naloxone following subsequent morphine withdrawal in addition to the physical signs characteristic of naloxone-precipitated withdrawal. Such increased mu constitutive activity may be an important component of the homeostatic response to opiate administration and subsequent abstinence and may therefore be a significant factor in mechanisms underlying the opiate addictive process. Since neutral antagonists were shown to be effective at blocking morphine, but produced less aversion and physical withdrawal in morphine-dependent animals, such drugs may prove more effective than naloxone or naltrexone in the treatment of opiate addiction by virtue of increased compliance.

\section{ACKNOWLEDGEMENTS}

This work was supported by the National Institutes of Health Grants DA 09359 (NTM) and DA 05010 (NTM), by the National Institute of Health Training Grant DA 09359 (JRS) and the Hatos Fellowship (JRS). We thank Drs Chris Evans, Brigitte Kieffer and Ping Law for helpful discussions during the preparation of this manuscript.

\section{REFERENCES}

Azar MR, Jones BC, Schulteis G (2003). Conditioned place aversion is a highly sensitive index of acute opioid dependence and withdrawal. Psychopharmacology (Berlin) 170: 42-50.

Bilsky EJ, Bernstein RN, Wang Z, Sadee W, Porreca F (1996). Effects of naloxone and D-Phe-Cys-Tyr-D-Trp-Arg-Thr-PenThr- $\mathrm{NH}_{2}$ and the protein kinase inhibitors H7 and H8 on acute morphine dependence and antinociceptive tolerance in mice. J Pharmacol Exp Ther 277: 484-490.

Blokhina EA, Sukhotina IA, Bespalov AY (2000). Pretreatment with morphine potentiates naloxone-conditioned place aversion in mice: effects of NMDA receptor antagonists. Eur J Pharmacol 406: 227-232.

Chatterjie N, Inturrisi CE (1975). Stereospecific synthesis of the 6beta-hydroxy metabolites of naltrexone and naloxone. J Med Chem 18: 490-492.

Cruz SL, Villarreal JE, Volkow ND (1996). Further evidence that naloxone acts as an inverse opiate agonist: implications for drug dependence and withdrawal. Life Sci 58: L381-L389.

Fukuda K, Kato S, Shoda T, Morikawa H, Mima H, Mori K (1998). Partial agonistic activity of naloxone on the opioid receptors expressed from complementary deoxyribonucleic acids in Chinese hamster ovary cells. Anesth Analg 87: 450-455.

Gracy KN, Dankiewicz LA, Koob GF (2001). Opiate withdrawalinduced fos immunoreactivity in the rat extended amygdala parallels the development of conditioned place aversion. Neuropsychopharmacology 24: 152-160.

Grevert P, Goldstein A (1977). Some effects of naloxone on behavior in the mouse. Psychopharmacology (Berlin) 53: 111-113.

Handal M, Grung M, Skurtveit S, Ripel A, Morland J (2002). Pharmacokinetic differences of morphine and morphine-glucuronides are reflected in locomotor activity. Pharmacol Biochem Behav 73: 883-892.

Iwamoto ET (1985). Place-conditioning properties of mu, kappa, and sigma opioid agonists. Alcohol Drug Res 6: 327-339.

Iwamoto K, Klaassen CD (1977). First-pass effect of morphine in rats. J Pharmacol Exp Ther 200: 236-244.

Kenakin T (2004). Efficacy as a vector: the relative prevalence and paucity of inverse agonism. Mol Pharmacol 65: 2-11.

Koob GF, Le Moal M (2001). Drug addiction, dysregulation of reward, and allostasis. Neuropsychopharmacology 24: 97-129.

Kreek MJ, Koob GF (1998). Drug dependence: stress and dysregulation of brain reward pathways. Drug Alcohol Depend 51: 23-47.

Liu JG, Prather PL (2001). Chronic exposure to mu-opioid agonists produces constitutive activation of mu-opioid receptors in direct proportion to the efficacy of the agonist used for pretreatment. Mol Pharmacol 60: 53-62.

Markou A, Weiss F, Gold LH, Caine SB, Schulteis G, Koob GF (1993). Animal models of drug craving. Psychopharmacology (Berlin) 112: 163-182.

Mucha RF, Herz A (1985). Motivational properties of kappa and $\mathrm{mu}$ opioid receptor agonists studied with place and taste preference conditioning. Psychopharmacology (Berlin) 86: 274-280. 
Mucha RF, Iversen SD (1984). Reinforcing properties of morphine and naloxone revealed by conditioned place preferences: a procedural examination. Psychopharmacology (Berlin) 82: 241-247.

Mucha RF, Millan MJ, Herz A (1985). Aversive properties of naloxone in non-dependent (naive) rats may involve blockade of central beta-endorphin. Psychopharmacology (Berlin) 86: 281-285.

Mucha RF, van der KD, O'Shaughnessy M, Bucenieks P (1982). Drug reinforcement studied by the use of place conditioning in rat. Brain Res 243: 91-105.

Mucha RF, Walker MJ (1987). Aversive property of opioid receptor blockade in drug-naive mice. Psychopharmacology (Berlin) 93: 483-488.

Parker LA, Cyr JA, Santi AN, Burton PD (2002). The aversive properties of acute morphine dependence persist $48 \mathrm{~h}$ after a single exposure to morphine. Evaluation by taste and place conditioning. Pharmacol Biochem Behav 72: 87-92.

Parker LA, Joshi A (1998). Naloxone-precipitated morphine withdrawal induced place aversions: effect of naloxone at $24 \mathrm{~h}$ postmorphine. Pharmacol Biochem Behav 61: 331-333.

Parker LA, Rennie M (1992). Naltrexone-induced aversions: assessment by place conditioning, taste reactivity, and taste avoidance paradigms. Pharmacol Biochem Behav 41: 559-565.

Raehal KM, Lowery JJ, Bhamidipati CM, Paolino RM, Blair JR, Wang $\mathrm{D}$ et al (2005). In vivo characterization of $6 \backslash\{$ betal\}naltrexol, an opioid ligand with less inverse agonist activity compared to naltrexone and naloxone in opioid dependent mice. $J$ Pharmacol Exp Ther (in press).

Schulteis G, Koob GF (1996). Reinforcement processes in opiate addiction: a homeostatic model. Neurochem Res 21: 1437-1454.
Aversion to $\mathrm{mu}$ antagonists and inverse agonists

Schulteis G, Markou A, Gold LH, Stinus L, Koob GF (1994). Relative sensitivity to naloxone of multiple indices of opiate withdrawal: a quantitative dose-response analysis. J Pharmacol Exp Ther 271: 1391-1398.

Seifert R, Wenzel-Seifert K (2002). Constitutive activity of G-protein-coupled receptors: cause of disease and common property of wild-type receptors. Naunyn Schmiedebergs Arch Pharmacol 366: 381-416.

Skoubis PD, Lam HA, Shoblock J, Narayanan S, Maidment NT (2005). Endogenous enkephalins, not endorphins, modulate basal hedonic state in mice. Eur J Neurosci 21: 1379-1384.

Skoubis PD, Matthes HW, Walwyn WM, Kieffer BL, Maidment NT (2001). Naloxone fails to produce conditioned place aversion in mu-opioid receptor knockout mice. Neuroscience 106: 757-763.

Wang D, Raehal KM, Bilsky EJ, Sadee W (2001). Inverse agonists and neutral antagonists at mu opioid receptor (MOR): possible role of basal receptor signaling in narcotic dependence. J Neurochem 77: 1590-1600.

Wang D, Raehal KM, Lin ET, Lowery JJ, Kieffer BL, Bilsky EJ et al (2004). Basal signaling activity of mu opioid receptor in mouse brain: role in narcotic dependence. J Pharmacol Exp Ther 308: 512-520.

Wang Z, Arden J, Sadee W (1996). Basal phosphorylation of mu opioid receptor is agonist modulated and $\mathrm{Ca}^{2+}$-dependent. FEBS Lett 387: 53-57.

Wang Z, Bilsky EJ, Porreca F, Sadee W (1994). Constitutive mu opioid receptor activation as a regulatory mechanism underlying narcotic tolerance and dependence. Life Sci 54: L339-L350.

Wang Z, Bilsky EJ, Wang D, Porreca F, Sadee W (1999). 3-Isobutyl1-methylxanthine inhibits basal mu-opioid receptor phosphorylation and reverses acute morphine tolerance and dependence in mice. Eur J Pharmacol 371: 1-9. 